\title{
Sulfate-bearing clay and Pietra Serena sludge: Raw materials for the development of alkali activated binders
}

\author{
Roberta Occhipinti $^{\mathrm{a}, 1}$, Ana M. Fernández-Jiménez ${ }^{\mathrm{b}}$, Angel Palomo ${ }^{\mathrm{b}}$, Serena C. Tarantino ${ }^{\text {c, d, *, }}$ \\ Michele Zema ${ }^{\text {a,d }}$

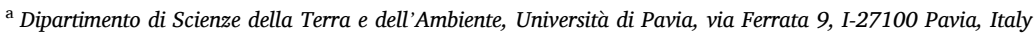 \\ ${ }^{\mathrm{b}}$ Instituto Eduardo Torroja (IETcC), CSIC, C/Serrano Galvache 4, 28033 Madrid, Spain \\ ${ }^{\mathrm{c}}$ Dipartimento di Chimica, Università di Pavia, viale Taramelli 12, I-27100 Pavia, Italy \\ ${ }^{d}$ CNR-IGG, Sezione di Pavia, via Ferrata 9, I-27100 Pavia, Italy
}

\section{A R T I C L E I N F O}

\section{Keywords:}

Secondary raw materials

Sulfate immobilization

Hybrid cement

Zeolites

\begin{abstract}
A B S T R A C T
The feasibility of transforming the residues of cultivation of two rocks into secondary raw materials through the alkali activation process has been assessed. Mixtures of a sulfate-bearing kaolinitic clay (L02-K) and a sludge derived by the sewing of Pietra Serena stone (sPS) have been investigated. These materials were preliminarily treated at high temperature to improve their reactivity (heat-treated samples are hereafter labelled as L02-MK and SPS-800). Pastes were prepared with mixtures of L02-MK and sPS-800 in different weight proportions by using $8 \mathrm{M} \mathrm{NaOH}$ solutions as alkaline activator and cured at $85^{\circ} \mathrm{C}$ for $24 \mathrm{~h}$. Mechanical strength was determined after 1, 7 and 28 days and the reaction products were characterized by XPRD, SEM/EDX and MAS-NMR. Sulfate solubility was quantified by leaching tests.

The alkali activation of the sole sulfate-bearing clay gives a material with developed mechanical strength of 4 (1) MPa. Some N-A-S-H gel forms together with gibbsite and thenardite, which can be easily leached. Better results are obtained by the activation of mixtures of the two precursors, and mixed alkali cements or hybrid cements are obtained. The presence of $\mathrm{CaO}$ from heat-treated Pietra Serena sludge improves the mechanical strength of the resulting pastes up to 11.8(9) MPa. In this case, a mixture of gels forms, specifically, a calciumrich gel (C-A-S-H-type) co-exists with (N,C)-A-S-H-type gel. U-phase and CAN-type zeolites also form. They trap sulfate from the clay and considerably reduce sulfate solubility. In conclusion, L02-MK and sPS-800 are promising raw materials for alkaline cements, whose properties may suggest application in soil stabilization or in waste confinement.
\end{abstract}

\section{Introduction}

Alkali Activated Materials (AAMs) have been intensively studied and promoted in the last decades as low-carbon binder alternatives to Portland-based cements, together with other materials such as carbonate and belite-ye'elimite-based binders, in response to growing global concerns over $\mathrm{CO}_{2}$ emissions from the construction sector.

A description of the state of the art related to these materials and recent developments, as well as a review of existing literature can be found in keynote papers [1,2] and books [3,4], and in the RILEM Technical Committee report edited by Provis \& van Deventer [5]. AAMs cements can enrich the portfolio of alternatives to Portland cement and contribute to the reduction of $\mathrm{CO}_{2}$ emissions in the construction sector if the possibility of producing and utilizing such materials is expanded, and their carbon footprint is reduced as well. It is therefore necessary to develop precursor-activator mixtures that respond to the following prerequisites: i) take the environmental footprint of the alkaline activator into particular account [6,7]; ii) overcome the obstacles linked to the supply chain; iii) mainly make use of minerals or industrial byproducts not currently used as a substitute for clinker in mixed cements. Therefore, it is worth exploiting the versatility and adaptability of AAMs in different geographical contexts, as they can be produced

\footnotetext{
* Corresponding author.

E-mail addresses: roberta.occhipinti01@universitadipavia.it (R. Occhipinti), anafj@ietcc.csic.es (A.M. Fernández-Jiménez), palomo@ietcc.csic.es (A. Palomo), serenachiara.tarantino@unipv.it (S.C. Tarantino), michele.zema@unipv.it (M. Zema).

1 Present address: Dipartimento di Scienze Biologiche, Geologiche e Ambientali, Università di Catania, Corso Italia 57, 95129 Catania, Italy.
} 
from a wide range of aluminosilicate precursors, with differing availability, reactivity, cost and value worldwide.

In this context, alkali activation can help sustain the challenge towards the transformation of the materials supply chain into a materials circle, a challenge that requires the development of innovative recycling and upcycling technologies as well as of environmental-friendly production and remanufacturing technologies.

Mining, metallurgical, societal and agricultural waste can be used as precursors or activators for alkali-activated binders, as documented by a consolidated body of literature (e.g., [8-21]). Large volumes of natural stones are extracted worldwide producing in turn large amounts of related wastes. The world production of dimension stone is estimated to be around 155 million tons [22]; six countries (namely, China, India, Turkey, Iran, Brazil and Italy) produce about $70 \%$ of the total world production of dimension stone. There is an urgent need to manage stone industry by-products in such a way that the environmental impact is minimized. Using these waste materials as construction materials appears to be a viable solution to the problem of waste accumulation and to generate cost reduction, while reducing the extraction of raw materials and preserving natural resources. The utilization of dimension stone sludge in alkali activation process has been recently reviewed [23]. Nonetheless, studies are needed in order to increase the use of these residues and to introduce new types of resources and industrial byproducts in the production chain. Consideration for the reduction of the $\mathrm{CO}_{2}$ footprint cannot disregard the minimization of the transport of bulk materials, as the emissions footprint of the binder can be highly affected by the distance and mode of transport [24,25].

Low- $\mathrm{CO}_{2}$ binders can find application in different fields depending on their mechanical strength development, for example as cements type CEM I or CEM II with high strengths at 28 days ( $<40 / 50 \mathrm{MPa}$ ), or as CEM III when strength values are around $35 \mathrm{MPa}$ at 28 days. Cements characterized by lower compressive strength values may find applications in soil stabilization or in confinement of toxic and/or hazardous waste [26-28].

In this work, two Italian materials were selected to determine their potential as precursors in alkali activation: a sulfate-bearing clay (L02$\mathrm{K}$ ) and sludge of ornamental sandstone rock Pietra Serena (sPS). The issues related to these materials are different.

sPS is a residual sludge from dimension stone processing that is mostly landfilled, representing a serious environmental and economic problem. If adequately treated, the sludge could be used as a secondary raw material, thus reducing landfilling and excavation of primary materials. Clausi et al. [29] have explored the possibility of using Pietra Serena sludge as a precursor in the alkaline activation process either alone or in binary mixtures with class F fly ashes and high-grade metakaolin, achieving encouraging results.

L02-K is a kaolinitic clay containing alunite, $\mathrm{KAl}_{3}\left(\mathrm{SO}_{4}\right)_{2}(\mathrm{OH})_{6}$, which normally hinders its use in the ceramic industry due to the release of $\mathrm{SO}_{3}$ at high temperature. However, alunite can be a valuable source of potassium and aluminum in alkali activation. In a previous study [30], the possibility of using L02-K to prepare geopolymers has been assessed by heat-treating this kaolin at temperature below desulfation [31]. However, the presence of thenardite, $\mathrm{Na}_{2} \mathrm{SO}_{4}$, deriving from the dissolution of alunite was observed in the final products. Other studies on the effects of sulfate on the alkali activation of fly ash, metakaolin and low-Ca ferronickel slag have indicated that the precipitation of some zeolites is enhanced, and the compressive strength of the resulting geopolymers is negatively affected [32-35].

The alkali activation process is extremely versatile and allows employing not only different materials as precursors but also more than one type of raw materials in synergy. Such studies will allow starting to build the bases for designing materials that may achieve a balance of commercial and technical goals and increase resource efficiency. With this in mind, the alkali activation of blends of these two little explored precursors were evaluated. In addition to the benefits of waste recovery, the combined use of sandstone sludge in binary mixtures with sulfate- bearing clay allowed exploring a multicomponent system of aluminosilicates containing sulfate and $\mathrm{Ca}$ in the presence of a solution of $\mathrm{NaOH}$. To understand the different mechanisms involved in the process, characterization of the reaction products was carried out by XRPD, SEM/ EDX and NMR as well as by sulfur leaching studies.

\section{Materials and methods}

\subsection{Starting materials}

\subsubsection{Sulfate-bearing kaolinitic clay}

Sulfate-bearing kaolinitic clay (labelled L02-K) from Piloni di Torniella quarry (Tuscany, Italy) was provided by Eurit s.r.l. (Italy). L02-K is composed by $26.0(3) \mathrm{wt} \%$ quartz, 47.6(7) wt $\%$ kaolinite, $19.0(5) \mathrm{wt} \%$ feldspars and 13.0(2) wt $\%$ alunite, as revealed by XRPD (Fig. 1). Its chemical composition (in oxide wt\%), as determined by X-ray fluorescence (XRF), is $\mathrm{SiO}_{2} 59.02 \%, \mathrm{Al}_{2} \mathrm{O}_{3} 22.85 \%, \mathrm{Fe}_{2} \mathrm{O}_{3} 1.26 \%$, $\mathrm{CaO} 0.11 \%$, $\mathrm{MgO} 0.12 \%, \mathrm{Na}_{2} \mathrm{O} 0.82 \%, \mathrm{~K}_{2} \mathrm{O} 3.30 \%, \mathrm{TiO}_{2} 0.28 \%$, and its measured ignition loss after calcinations at $1000{ }^{\circ} \mathrm{C}$ for one hour is $12.07 \%$ (the theoretical value for pure kaolinite is $13.96 \%$ ). Sulfate content is $5.2 \mathrm{wt}$ $\%$, as quantified by Combustion Infrared Detection by using an Eltra CS2000 analyzer. All chemical analyses were carried out at Activation Laboratories Ltd. (Canada).

Particle size distribution of L02-K was determined (in ethanol) by using a Malvern Mastersizer S particle size analyzer equipped with a laser diffraction sensor. A bimodal distribution was found: $50 \%$ of particles have size below $8.5 \mu \mathrm{m}$, whereas $90 \%$ are below $45 \mu \mathrm{m}$.

L02-K was treated at $550{ }^{\circ} \mathrm{C}$ for $3 \mathrm{~h}$ in order to transform kaolinite into metakaolinite (hereafter labelled L02-MK) and to induce alunite dehydroxylation, which in turn generates $\mathrm{K}$-alum, $\mathrm{KAl}\left(\mathrm{SO}_{4}\right)_{2}$, and amorphous alumina. XRPD pattern of L02-MK is reported in Fig. 1. After thermal treatment, only peaks related to quartz and feldspars are found. A study making use of a different batch of this kaolinitic clay to synthetize geopolymers has been reported by Gasparini et al. [30].

\subsubsection{Pietra Serena sludge}

Pietra Serena is a feldspathic litharenite and sludge of this sandstone (labelled sPS) was provided by Pietra Serena Group s.r.l. (Firenzuola, Italy). Mineralogical and chemical compositions and particle size distribution data have been given by Clausi et al. [29], and are reported hereafter. Mineralogical composition includes quartz, albite, anorthite, clinochlore, muscovite, calcite and dolomite. Chemical composition is $\mathrm{SiO}_{2}$ 43.50\%, $\mathrm{Al}_{2} \mathrm{O}_{3}$ 8.28\%, $\mathrm{Fe}_{2} \mathrm{O}_{3}$ 2.44\%, $\mathrm{CaO} 19.53 \%, \mathrm{MgO} 4.19 \%$, $\mathrm{Na}_{2} \mathrm{O} 1.46 \%, \mathrm{~K}_{2} \mathrm{O} 1.74 \%, \mathrm{TiO}_{2} 0.42 \%, \mathrm{SO}_{3} 0.18 \%$, and its loss on ignition is $18.0 \%$. Particle size distribution is unimodal and ranges between 0.3 and $90 \mu \mathrm{m}$.

The sludge was thermally treated at $800^{\circ} \mathrm{C}$ for $2 \mathrm{~h}$ (the resulting sample is labelled sPS_800) in order to decompose carbonates. Fig. 1 shows the XRPD patterns of sPS before [taken from Fig. 3a in ref. 17] and after thermal treatment (sPS_800). After heating, peaks related to clinochlore, calcite and dolomite are not present and carbonate decomposition is confirmed by the presence of lime $(\mathrm{CaO})$ and periclase $(\mathrm{MgO})$.

\subsection{Reactivity of starting materials by HF attack}

L02-K, L02-MK and sPS_800 were treated with a $1 \%$ HF solution. This selective chemical attack, proposed by Ruiz-Santaquiteria et al. [36], dissolves the amorphous phases and slightly affects the crystalline ones (e.g., quartz, feldspar), thus allowing to determine the amount of reactive silica and alumina. The amounts of silica and alumina released in the leachates solution were determined by means of ICP-AES. The total amounts of soluble phases were determined gravimetrically in L02-K and L02-MK but not in SPS_800, because $\mathrm{CaO}$ reacts with HF producing calcium fluoride as by-product. Results are reported in Table 1.

The XRPD patterns of the insoluble residues obtained after HF attack (showing the suffix _HF in sample labels) are shown in Fig. 1 and 

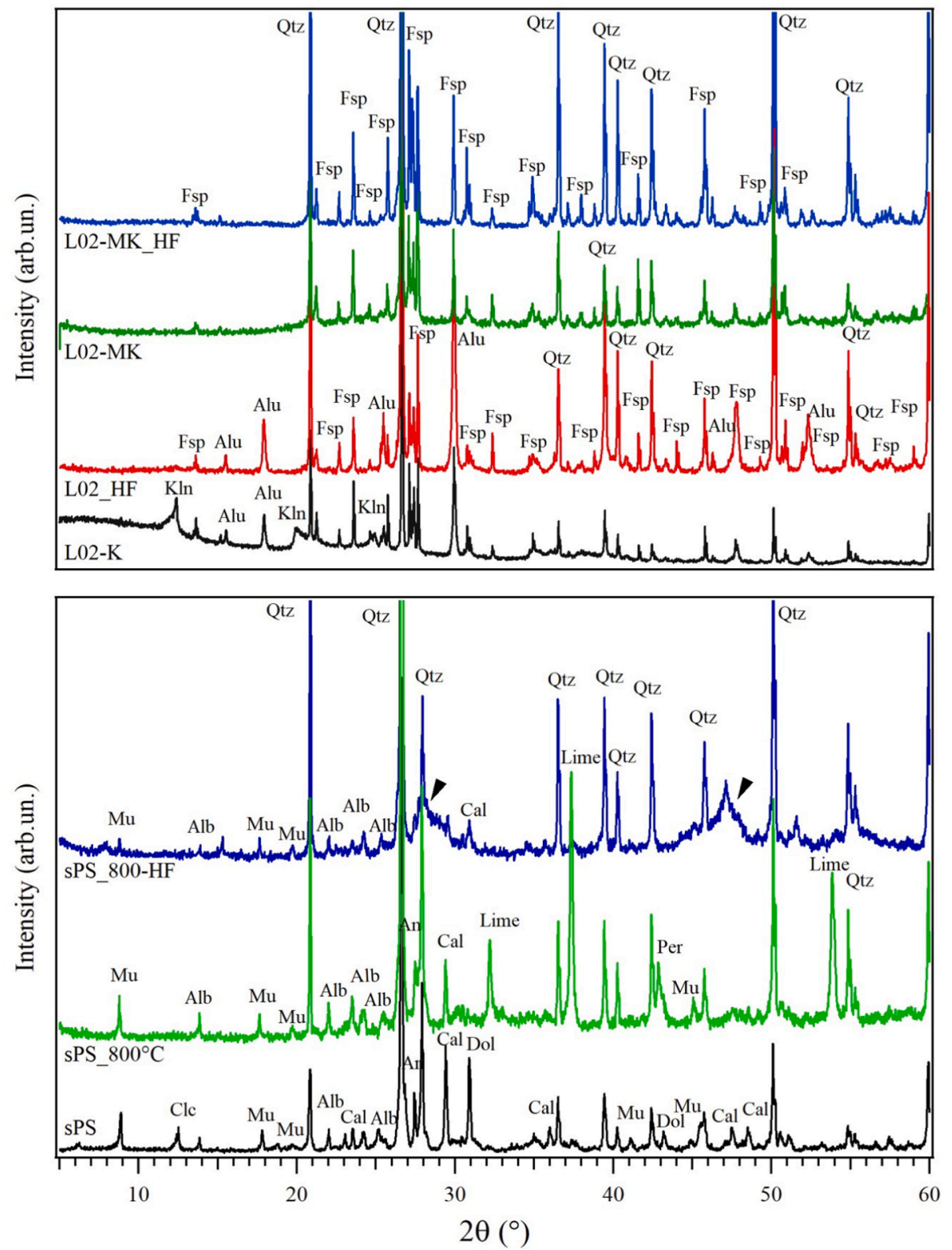

Fig. 1. XRPD patterns. Top panel: L02-K (black), L02-MK (green), L02-K_HF (red) and L02-MK_HF (blue); bottom panel: sPS (black), sPS_800 (green) and sPS_800_HF (blue). Alb = Albite (PDF \#74-0603); An = Anorthite (PDF \#86-1707); Cal = Calcite (PDF \#81-2027); Clc = Clinochlore (PDF \#74-1137); Dol = Dolomite (PDF \#83-1766); $\mathrm{Mu}=$ Muscovite (PDF \#77-2255); Qtz = Quartz (PDF \#83-0539); Alu = Alunite (PDF \#47-1885); Fsp = Feldspars (PDF \#71-1544); Kln = Kaolinite (PDF \#78-2110). The arrow indicates calcium fluoride precipitated after HF attack. (For interpretation of the references to color in this figure legend, the reader is referred to the web version of this article.)
Table 1

Amounts (wt\%) of precursors solubilized by selective chemical attack and of reactive silica and alumina in precursors.

\begin{tabular}{lllr}
\hline & Soluble phase & $\mathrm{SiO}_{2}$ & $\mathrm{Al}_{2} \mathrm{O}_{3}$ \\
\hline L02-K & 59 & 22.3 & 16.8 \\
L02-MK & 63 & 22.2 & 20.8 \\
sPS_800 & n.d. & 13.7 & 3.0 \\
\hline
\end{tabular}

compared with those of the same materials before chemical treatment. From the graphs, it is possible to observe that diffraction peaks of quartz, feldspars and plagioclase are still present after acid attacks in all patterns. The absence of kaolinite peaks in the L02-K_HF pattern indicates its dissolution in the acidic medium. Alunite peaks, which are evident in sample L02-K_HF, are not present in L02-MK_HF. The larger amount of aluminum in the solution leached from L02-MK than in that obtained from L02-K (Table 1) is therefore due to the dissolution of the products deriving from alunite dehydroxylation, anhydrous alum and $\mathrm{Al}_{2} \mathrm{O}_{3}$, which are more soluble than alunite itself in the acidic medium.
XRPD pattern of the solid residue of sPS_800_HF shows the diffraction peaks of muscovite and anorthite, but not those of lime, which is present in the sPS_800 sample. In the ranges between $28^{\circ}$ and $30^{\circ} 2 \theta$ and $46-49^{\circ} 2 \theta$, broad peaks are indicative of the formation of calcium fluoride.

\subsection{Alkaline cement paste preparation}

Powders of L02-MK and sPS_800 were mixed in different weight proportions (100/0, 90/10 and 50/50) and allowed to react with $8 \mathrm{M}$ $\mathrm{NaOH}$ solution using a liquid/solid ratio (L/S, weight percent) giving a satisfactory workability. In the $\mathrm{L} / \mathrm{S}$ ratio, $\mathrm{L}$ takes into account the mass of $\mathrm{H}_{2} \mathrm{O}$ added as such and that brought from the activator solution, whereas $\mathrm{S}$ is the total mass of the materials in the solid phase (L02-MK and SPS_800) and the solid part in the alkaline activators. Resulting products are labelled L02-100-8M, L02-90-sPS-8M and L02-50-sPS-8M, respectively. Details of sample preparation are reported in Table 2.

Sodium hydroxide solutions were obtained by dissolving $\mathrm{NaOH}$ pellets (Sigma-Aldrich Co.; reagent grade $\geq 98 \mathrm{wt} \%$ ) in deionized water. 
Table 2

Synthetic and resulting chemical details of the alkaline pastes.

\begin{tabular}{clllllll}
\hline Samples & $\begin{array}{l}\text { Clay/ } \\
\text { sPS }\end{array}$ & $\mathrm{L} / \mathrm{S}$ & \multicolumn{2}{l}{ Oxides molar ratios } \\
$\mathrm{SiO}_{2} /$ & $\begin{array}{l}\mathrm{CaO} / \\
\mathrm{Al}_{2} \mathrm{O}_{3}\end{array}$ & $\begin{array}{l}\mathrm{SiO}_{2} \\
\mathrm{Si}_{2} /\end{array}$ & $\begin{array}{l}\mathrm{Nl}_{2} \mathrm{O}_{3} / \\
\mathrm{Na}_{2} \mathrm{O}\end{array}$ & $\begin{array}{l}\mathrm{SO}_{4} / \\
\mathrm{CaO}\end{array}$ \\
\hline $\begin{array}{c}\text { L02-100- } \\
8 \mathrm{M}\end{array}$ & $100 / 0$ & 0.26 & 1.8 & - & 3.2 & 1.7 & - \\
$\begin{array}{c}\text { L02-90- } \\
\text { sPS-8M }\end{array}$ & $90 / 10$ & 0.30 & 1.9 & 0.7 & 2.7 & 1.4 & 1.15 \\
$\begin{array}{c}\text { L02-50- } \\
\text { sPS-8M }\end{array}$ & $50 / 50$ & 0.45 & 2.5 & 0.5 & 1.9 & 0.8 & 0.13 \\
\hline
\end{tabular}

The slurries were mixed for $3 \mathrm{~min}$ by using a mechanical mixer before being poured in $1 \times 1 \times 6 \mathrm{~cm}^{3}$ prismatic steel molds and cured in an oven at $85{ }^{\circ} \mathrm{C}$ for $24 \mathrm{~h}$ in sealed vessels to ensure $100 \%$ Relative Humidity before being demolded. The specimens were subsequently removed from the molds and stored in the climatic chamber $\left(22 \pm 2{ }^{\circ} \mathrm{C}\right.$ and relative humidity greater than $90 \%$ ) until they reached the test age (1, 7 or 28 days).

After curing, samples were tested for compressive strength after 1 day, 7 and 28 days. Selected samples were characterized by X-ray Powder Diffraction (XRPD), Scanning Electron Microscopy (SEM/EDX), Nuclear Magnetic Resonance (MAS-NMR). Sulfate-bearing samples were also examined by leaching tests accompanied by ICP-AES analysis of leachates.

\subsection{Characterization methods}

Compressive strengths were determined on an Ibertest Autotest-200/ 10 -SW test frame. For each sample, the compressive strength value given in Fig. 2 is the average of twelve specimens.

XRPD patterns were recorded by a Bruker D8 Advance diffractometer. The operating conditions were $40 \mathrm{kV}$ and $30 \mathrm{~mA}$; instrumental conditions were: $\mathrm{CuK} \alpha_{1,2}$ radiation without monochromator; variable 6$\mathrm{mm}$ divergence slit; $2 \theta$ angle $5-60^{\circ}$; step time $0.5 \mathrm{~s}$; angular step $0.02^{\circ}$ $2 \theta$.

A SEM JEOL JSM 5400 equipped with an OXFORD Instruments ISIS Link EDX spectrometer was utilized to investigate the microstructure of samples. Analyses were performed, in vacuum mode, on fracture surfaces of the specimens covered by carbon coating. Images were collected using secondary electron (SE) at working distance of $15 \mathrm{~mm}$ with an acceleration voltage of $20 \mathrm{kV}$. EDX analyses (on spots) were done with accelerating voltage of $20 \mathrm{kV}$, working distance of $15 \mathrm{~mm}$ and beam current of $20 \mu \mathrm{A}$, and acquiring for $30 \mathrm{~s}$ per spot analysis. Chemical compositions were determined considering $100 \mathrm{wt} \%$ oxide content on

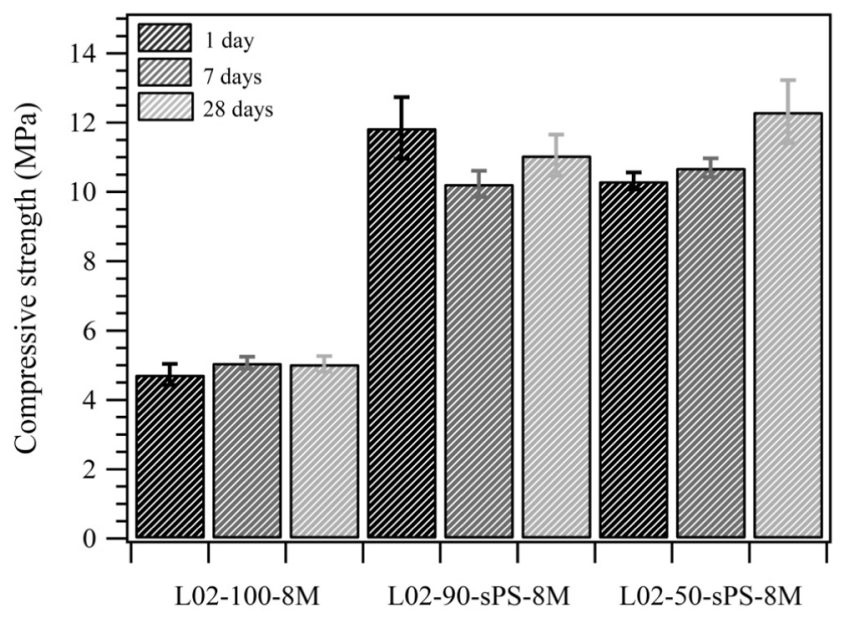

Fig. 2. Compressive strength of the different alkali activated specimens after 1 day, 7 days and 28 days (average of twelve tests). an $\mathrm{H}_{2} \mathrm{O}-$ and $\mathrm{CO}_{2}$-free basis.

NMR spectra were recorded on a Bruker Avance- 400 spectrometer $\left({ }^{27} \mathrm{Al}\right.$ : $104.3 \mathrm{MHz}$; spinning rate $10 \mathrm{kHz} ; 200$ acquisitions; reference: $\mathrm{Al}$ $\left(\mathrm{H}_{2} \mathrm{O}\right)_{6}^{3+} ;{ }^{29} \mathrm{Si}$ : $79.5 \mathrm{MHz}$; spinning rate $10 \mathrm{kHz} ; 1000$ acquisitions; reference: tetramethylsilane, TMS).

Leaching tests were performed according to UNI-EN 1245 standard. After alkali activation, one powdered sample for each series was mixed with distilled water (with a liquid-to-solid ratio of $20 \mathrm{ml} / \mathrm{g}$ ) into $50 \mathrm{ml}$ PP centrifuge tubes, and shaken on a rotating plate $(150 \mathrm{rpm})$ at room temperature for $24 \mathrm{~h}$ to ensure equilibration. Sulfates equilibrium concentrations were measured on the centrifuged ( $4500 \mathrm{rpm}, 15 \mathrm{~min}$ ) and filtered $(0.45 \mu \mathrm{m}$ nylon membrane) samples by ICP-AES.

ICP-AES analyses were carried out by a Varian 725-ES ICP atomic emission spectrometer at the following conditions: plasma power, 1.40 $\mathrm{kW}$; plasma gas flow, $15.00 \mathrm{l} / \mathrm{min}$; nebulizer gas flow, $0.85 \mathrm{l} / \mathrm{min}$; read time, $5 \mathrm{~s}$.

\section{Results and discussions}

\subsection{Mechanical properties}

Compressive strength values for samples with different clay/sludge ratios at different ages are reported in Fig. 2. By comparing samples at one day of curing, it is evident how mechanical strength is very low for L02-100-8M, while when L02-MK is used in blends with sPS_800, mechanical strength increases significantly. The addition of $10 \mathrm{wt} \%$ of sPS_800 to L02-MK causes a tripling of the compressive strength. However, a further increase of sPS_800 content in the mixture to $50 \mathrm{wt} \%$ does not increase further the compressive strength of the cured cement.

The mechanical strengths of samples aged 7 and 28 days do not show a significant increase with respect to those of samples at 1 day of curing. An important factor observed during the preparation of L02-50-sPS-8M was the fast hardening of the slurry, such that it was difficult to pour it into the molds. This may have in turn affected the strength of the final product, and indicates that $\mathrm{CaO}$ plays an important role in the development of strength, as it will be discussed later.

\subsection{X-ray powder diffraction}

XRPD patterns of samples after one day of curing are displayed in Fig. 3. No significant differences have been detected in patterns from samples with longer setting times and therefore, these are not reported. In figure, the XRPD pattern of the anhydrous mixture of L02-MK and sPS_800 is also reported for comparison.

In addition to quartz and feldspars from the original precursors, all the binders show a signal related to the X-ray amorphous aluminosilicate gel [37-39], recognizable by a more or less marked halo between $20^{\circ}$ and $35^{\circ} 2 \theta$.

The XRPD pattern of sample L02-MK-8M_1D shows peaks of thenardite (PDF: \#070-1541) and gibbsite (PDF: \#070-2038). Crystals of thenardite were also macroscopically detected as efflorescence on the surface of the sample just few hours after demolding. The presence of gibbsite suggests that aluminum available from the starting materials is not entirely involved in the gel formation and part of it precipitates as crystals. This can largely justify the low mechanical strength developed by this paste. No crystalline zeolites were detected.

In all samples containing sPS_800, a sulfate-bearing cancrinite, namely vishnevite (PDF: \#046-1333), is formed. Peaks related to YUG-type zeolite (PDF: \#039-1372), a calcium aluminosilicate hydrate compound, are also detected in L02-90-sPS-8M_1D. In L02-50-sPS-8M_1D, in addition to vishnevite, sulfate-bearing SOD-type zeolites (PDF: \#073-1734) and Uphase (sodium calcium sulfoaluminate, PDF: \#044-0272) are found. The latter belongs to AFm family of compounds, hydrated calcium sulfoaluminate phases occurring in hydrated cement paste [40-42], and contains sodium between the layers. Several peaks not well matched and related to a poorly crystalline calcium silicate hydrate phase (C-S-H) like killalaite 


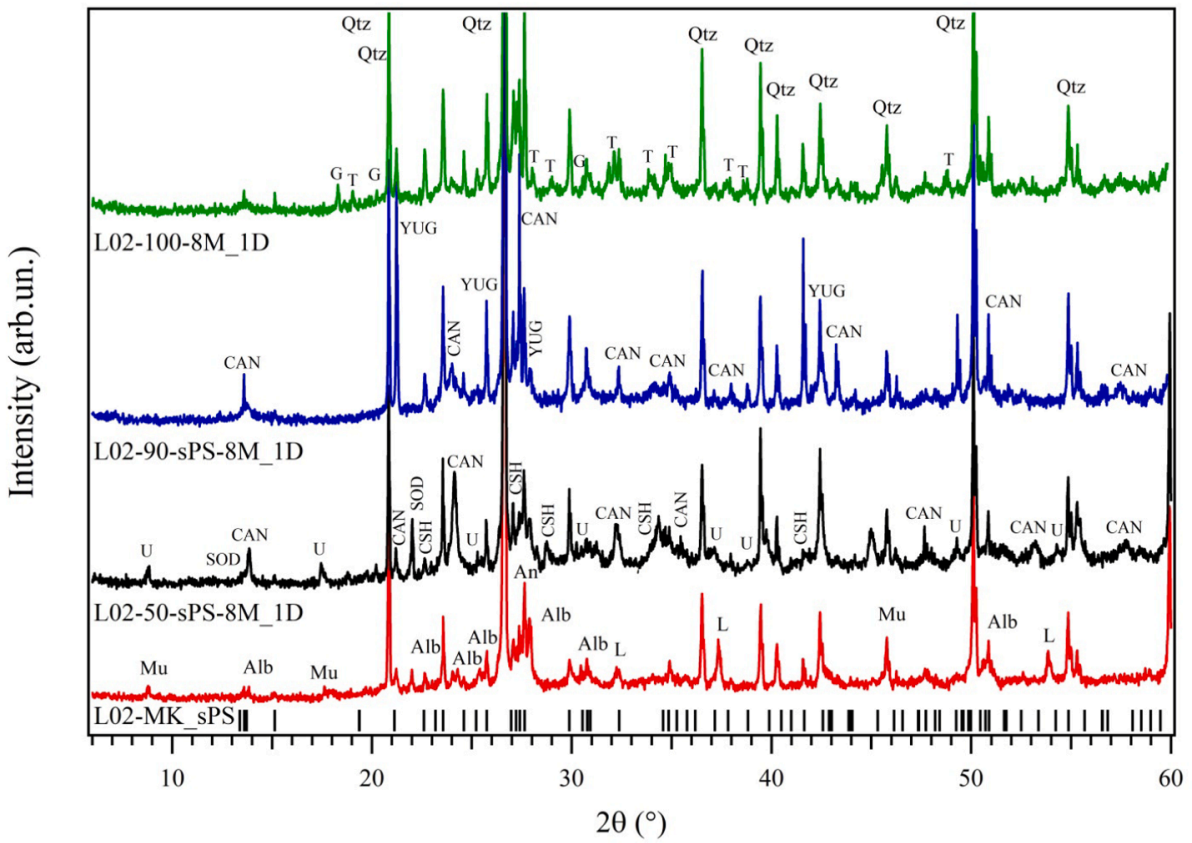

Fig. 3. XRPD patterns of samples L02-100-8M_1D (green), L02-90-sPS-8M_1D (blue) and L02-50-sPS8M_1D (black); XRPD pattern of a L02-MK/sPS_800 mechanic mixture before alkali activation is also shown for comparison (red line). Black bars indicate the positions of feldspars reflections. $\mathrm{G}=$ Gibbsite; $\mathrm{T}$ = Thenardite; Qtz = Quartz; CAN = CAN-type zeolite, $\mathrm{CSH}=$ Killalaite, $\mathrm{U}=\mathrm{U}$-Phase, SOD = SODtype zeolite; YUG = YUG-type zeolite; $\mathrm{Mu}=$ Muscovite, Alb = Albite; L = Lime. (For interpretation of the references to color in this figure legend, the reader is referred to the web version of this article.)
(PDF: \#029-0332) are evident. C-S-H phases are not detected in the binder with $10 \mathrm{wt} \%$ of sPS_800. It is interesting to note that some of the phases observed in L02-50-sPS-8M_1D are similar to those observed in the hydration of a Portland cement, such as poorly crystalline C-S-H gel, AFt or AFm $[40,43]$.

\subsection{Scanning electron microscopy}

SEM-EDX investigations have been carried out to evaluate differences in morphology and chemical compositions of gel or gels formed in the three systems with changing SPS_800 content. Micrographs of L02100-8M_1D, L02-90-sPS-8M_1D and L02-50-sPS-8M_1D samples are shown in Fig. 4.

At low magnification (450x), micrograph of L02-100-8M_1D (Fig. 4a) shows the hardened matrix; a heterogeneous porosity is also evident. Fig. 4a shows a spherical void of $100 \mu \mathrm{m}$ in size probably due to air bubbles trapped in the matrix during the synthesis; the pore is filled by several gibbsite crystals, which cover also several other pores. A magnified image of the gibbsite crystals and the relative EDX spectrum are reported in the inset of Fig. 4a and in Fig. 4a1, respectively. The presence of crystals inside the voids should not influence the mechanical strength. At this scale, well-shaped thenardite crystals have not been found, however, the high sodium and sulfur content reported in the EDX spectrum (Fig. $4 \mathrm{a} 2$ ) could be due to the occurrence of $\mathrm{Na}_{2} \mathrm{SO}_{4}$.

The matrix of L02-100-8M_1D (Fig. 4b) displays the distinctive granular features of N-A-S-H gel. Ultra-fine particles seem to be confined into isolated elements and partially bonded together. The morphological features of the gel are similar to those of zeolites at very early stages of crystallization, and this leads to suggest N-A-S-H as amorphous precursor of zeolites [44].

EDX spot analyses revealed a certain variability of N-A-S-H gel composition, as evident in Fig. 4b1 and Fig. 4b2. Local enrichment in $\mathrm{Si}$ content of the gel at the expenses of $\mathrm{Al}$ might be explained by the presence of gibbsite. The hypothesis is that aluminum from dehydroxylated alunite might dissolve more quickly than aluminum and silicon from metakaolin. The former reacts to form N-A-S-H gels and, possibly, zeolites as silica dissolves from metakaolin. The medium might be locally saturated in aluminum, which precipitates as gibbsite in the presence of $\mathrm{OH}$. The presence of thernardite implies a reduced availability of the activator and hence a reduced amount of gel formed.
Micrographs of L02-90-sPS-8M_1D (Fig. 4c-d) clearly display the differences in microstructure of this sample with respect to L02-1008M_1D. At low magnification (Fig. 4c), L02-90-sPS-8M_1D exhibits a compact matrix with precipitation of several acicular crystals, likely CAN-type zeolites also detected by XRPD. Deng et al. [45] have found that rod-shaped crystalline cancrinite may form from alkaline Si-rich solutions when $\mathrm{Na}_{2} \mathrm{SO}_{4}$ is present. At higher magnification $(12 \mathrm{Kx}$; Fig. 4d), it is possible to observe some differences in the morphology of the aluminosilicate gel: on the left part of the image, the gel seems more granular with concatenated spherical particles creating small clusters; on the right, it seems that such clusters have grown and form a more interconnected matrix. In both areas, a layered morphology, a wellknown feature of metakaolin-derived gel, is evident. The morphological differences subtend also small differences in chemical composition as evidenced by EDX analyses (insets $\mathrm{d} 1$ and $\mathrm{d} 2$ ). Both spectra indicate the presence of an aluminosilicate gel with partial replacement of $\mathrm{Na}^{+}$ ions by $\mathrm{Ca}^{2+}$ ions, forming a (N,C)-A-S-H gel. The substitution is higher in the small-sized gel on the left part of the image. Sulfur is present in the matrix and is higher in the Na-richer gel.

Fig. 4e-f show micrographs relative to L02-50-sPS-8M_1D. Inspection of Fig. $4 \mathrm{e}(5.0 \mathrm{Kx})$ confirms the development of a gel, which is characterized by an inhomogeneous microstructure as also confirmed by the image at higher magnification (Fig. 4f). In Fig. 4e, the contribution of $\mathrm{CaO}$ hydration is evidenced by the occurrence of some elongated particles not interconnected and distributed on the surface. A layered morphology is also present on the lower right part of the image. At 10.0 Kx (Fig. 4f), the cement microstructure appears composed by needleshaped elements and small crystalline hexagonal prisms, which resemble zeolites, likely cancrinite. The acicular particles are distinctive of the early crystallization stages of calcium silicate hydrated compounds (C-S-H) $[46,47]$, and similar microstructure and composition have been found in literature in AAMs prepared by using sandstone sediments $[48,49]$. EDX spectra (see insets $\mathrm{f} 1$ and $\mathrm{f} 2$ in Fig. 4) show the formation of two compositionally different gels. One is a C-A-S-H gel (with small amount of sodium), with $\mathrm{SiO}_{2} / \mathrm{Al}_{2} \mathrm{O}_{3}$ molar ratio of 2.5 and $\mathrm{CaO} / \mathrm{SiO}_{2}$ molar ratio of 1.34 , and the other is a (N,C)-A-S-H gel with a $\mathrm{SiO}_{2} / \mathrm{Al}_{2} \mathrm{O}_{3}$ molar ratio of 3.3 and $\mathrm{CaO} / \mathrm{SiO}_{2}$ molar ratio of 0.6 . In this sample, sulfur forms U-phase, whose crystals have not been detected by SEM, nonetheless EDX analyses seem to indicate that it is part of the gel matrix as well. 

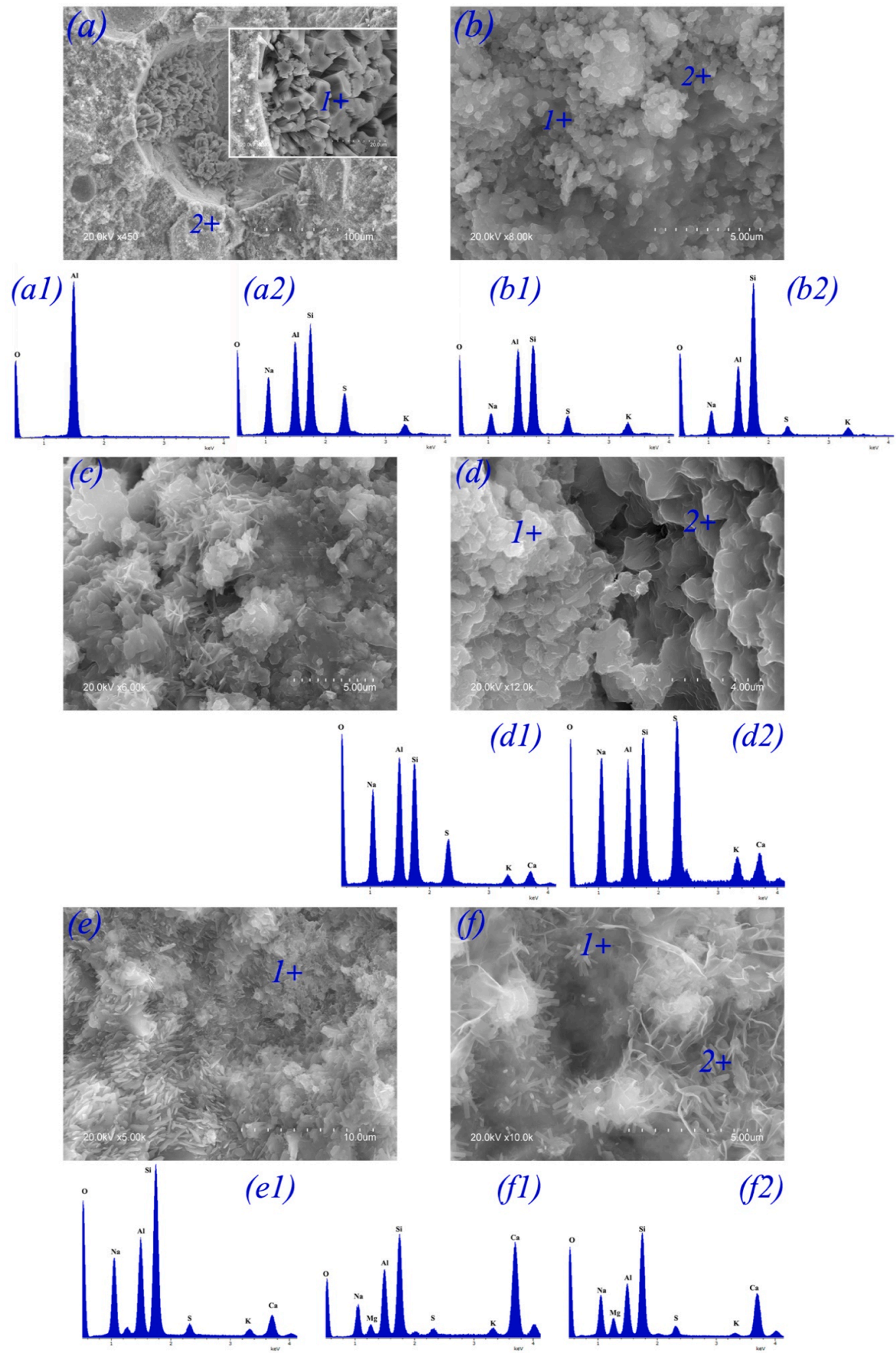

Fig. 4. SE-Micrographs and EDS analyses of the different alkali activated specimens after 1 day of curing. Scale bars and magnifications are shown in the images. a-b) L02-100-8M_1D, c-d) L02-90-sPS-8M_1D and e-f) L02-50-sPS-8M_1D.

\subsection{1. $\mathrm{Al}_{2} \mathrm{O}_{3}-\mathrm{SiO}_{2}-\mathrm{CaO}$ ternary diagrams}

A high number of EDX spot analyses (over 30 for each sample) have been conducted to evaluate variations in the composition of the gel phases. These are reported in the $\mathrm{SiO}_{2}-\mathrm{Al}_{2} \mathrm{O}_{3}-\mathrm{CaO}$ ternary diagrams in
Fig. 5a-c. In the diagram relative to L02-100-8M_1D, points clearly cluster in the left part of the diagram along the $\mathrm{SiO}_{2}-\mathrm{Al}_{2} \mathrm{O}_{3}$ line (Fig. 5a). Inspection of Fig. $5 \mathrm{~b}$ and Fig. $5 \mathrm{c}$ confirms the variability in composition of the gel or gels formed when sPS_800 is admixed to the sulfate-bearing 


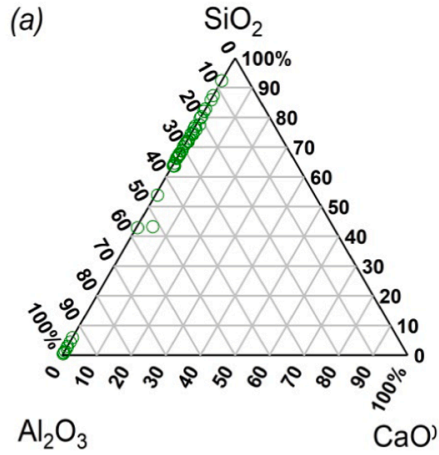

L02-100-8M

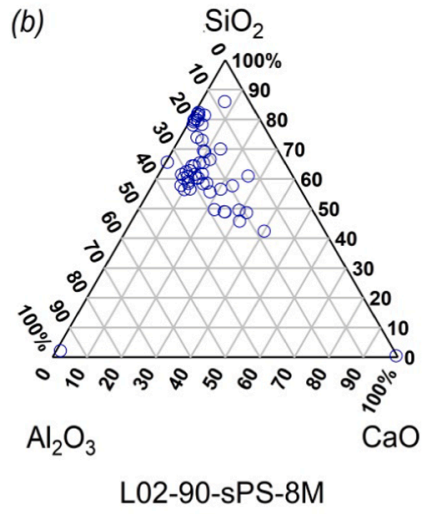

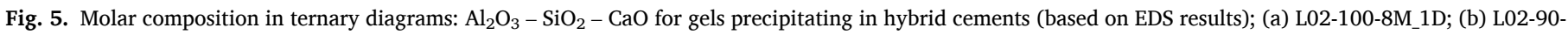
sPS-8M_1D; (c) L02-50-sP-8M_1D.

clay, although these data are semi-quantitative. As expected, in this type of multi-component systems, the main reaction product is a mix of gels: (N,C)-A-S-H and C-A-S-H. The precipitates contain post-dissolution ionic species, in the original N-A-S-H gel, much of the sodium was replaced by calcium as a result of well-known ionic exchange mechanisms [50-52]. The resulting product is an intermediate gel. Clearly, as reported in literature $[53,54]$, the co-existence of C-A-S-H and (N,C)-A-S-H gels and the prevalence of one over the other depend on the calcium content. Diagram in Fig. 5b shows that in L02-90-sPS-8M_1D, gel composition ranges within the field of high aluminum (N,C)-A-S-H. The greater dispersion of points in the diagram in Fig. 5b suggests a larger heterogeneity in gels forming the L02-50-sPS-8M_1D paste with compositions extending to C-A-S-H.

\section{4. ${ }^{27}$ Al and ${ }^{29}$ Si nuclear Magnetic Resonance}

In order to evaluate the structure at short-range length scale of the original metakaolin and of the various gels formed in the alkaliactivated binders, MAS-NMR spectroscopy was used for examining the local environment of ${ }^{27} \mathrm{~A} 1$ and ${ }^{29} \mathrm{Si}$ (Fig. 6a-h).

\subsection{1. ${ }^{27}$ Al MAS-NMR spectra}

The ${ }^{27} \mathrm{Al}$ spectra were analyzed by using DMFIT software [43] to take the quadrupolar parameter into account. However, in this paper, only isotropic chemical changes $\left(\delta_{\text {iso }}\right.$ ) were considered.

${ }^{27}$ Al MAS-NMR spectra from all samples (Fig. 6) show one dominant peak at around $60 \mathrm{ppm}$ mainly from tetrahedral aluminum. This peak in the spectrum from L02-MK has an asymmetric peak shape, which may indicate the overlap of tetrahedral aluminum of different environments. The spectrum was fitted by using the Czjzek model [55] to take into account a distribution of the quadrupolar interaction reflecting the structural disorder at short length scale. The fit of ${ }^{27} \mathrm{Al}$ MAS-NMR spectrum from L02-MK (Fig. 6a) before activation reveals the presence of Al in tetrahedral $(\delta=70-50 \mathrm{ppm})$, fivefold ( $\delta=30-40 \mathrm{ppm})$ and octahedral $(\delta=-20-0 \mathrm{ppm})$ coordinations. This signal reflects the amorphous nature of the starting metakaolinite, in which Al occupies preferably four- and five-fold structural positions, whereas occupation of octahedral coordination sites is lower [56-58]. Octahedral aluminum can also be associated to the presence of $\mathrm{Al}_{2} \mathrm{O}_{3}[59,60]$ ( $\left.\delta=10-15 \mathrm{ppm}\right)$ and anhydrous alum $\mathrm{KAl}\left(\mathrm{SO}_{4}\right)_{2}$ deriving from the dehydroxilation of alunite [61].

The spectra from the alkali activated pastes were fitted considering first order quadrupolar interaction and by using Lorentian lines. The Al (4Si) sites in alkali activated pastes (Fig. 6a-d) exhibit ${ }^{27} \mathrm{Al}$ chemical shifts in the range 50-65 ppm. This range suggests that $\mathrm{AlO}_{4}$ tetrahedra are present and likely surrounded by three or four silicon atoms. The symmetry of this signal and the fact that it is narrower than in the resonances of the starting materials suggest its possible association with tetrahedral aluminum, $\mathrm{Al}(\mathrm{IV})$. This resonance is probably due to an overlay of tetrahedral $\mathrm{Al}$ within the framework of the zeotypes, with tetrahedral $\mathrm{Al}$ present in the N-A-S-H, (N,C)-A-S-H and C-A-S-H type cementing gels described in the literature $[56,62]$. Penta-coordinated aluminum is not detected in any of the alkali-activated samples. This observation strongly indicates that almost all of the $\mathrm{Al}(\mathrm{V})$ species in the starting materials have been dissolved during the alkaline activation process. However, a small signal from $\mathrm{Al}(\mathrm{VI})$ sites is observed. In L02MK-100-8M_1D sample (Fig. 6b), the signal appears at $9.6 \mathrm{ppm}$ and can be associated to crystalline gibbsite [63], also detected by XRPD. Nevertheless, in the samples with sPS_800 (L02-MK-90-sPs-8M_1D and L02-MK-50-sPs-8M_1D; Fig. 6c and 6d, respectively), the signal has low intensity and appears near to $10.5 \mathrm{ppm}$, associated to the formation of AFm phases as U-Phase [64].

\subsection{2. ${ }^{29}$ Si MAS-NMR spectra}

The ${ }^{29}$ Si MAS-NMR spectrum from L02-MK (Fig. 6e) shows a broad and poorly defined signal, reflecting the structural disorder and heterogeneous coordination distribution of the silicon atoms in the dehydroxylated clay. The sharp peak at $-108 \mathrm{ppm}$ is associated to the presence of quartz $[56,65]$ in the original material, and is present without change in the spectra from the alkali activated samples.

A significant change is observed in the appearance of the resonances for the blends after alkali activation (Fig. 6f-h), an indication that chemical and structural transformations take place in the process. The presence of calcium in the mixtures gives rise to sharper signals (Fig. 6g-h). Moreover, with increasing $\mathrm{Ca}$, the center of gravity of the main envelope shifts towards less negative values. This may suggest the formation of less polymerized gels, e.g., (N,C)-A-S-H and C-A-S-H [62]. The signals reveal the existence of a number of distinct features; however, they cannot be readily interpreted because of the overlap among resonances due to silicon sites in the unreacted materials, in the cementitious gel/gels, and in the zeolites formed during alkali activation. Interpretation of deconvoluted spectra for ${ }^{29} \mathrm{Si}$ MAS-NMR and the assignment of the peaks is less straightforward for the samples containing calcium. For example, the signal at $-89 \mathrm{ppm}$ in the sample L02-100-8M_1D (Fig. 6f) can be associated with both $\mathrm{Q}^{4}(3 \mathrm{Al})$ units from the N-A-S-H gel-like structures and/or zeolites, while in the L02-90-sPS-8M_1D and in the L02-50-sPS-8M_1D samples it may also be due to the presence of $\mathrm{Q}^{3}(3 \mathrm{Al})$ units (Fig. $6 \mathrm{~g}-\mathrm{h}$ ) in C-A-S-H.

In the ${ }^{29} \mathrm{Si}$ spectrum from the original metakaolin L02-MK (Fig. 6e), five signals are detected. The spectrum can be interpreted in terms of resonances associated to $\mathrm{Q}^{4}(\mathrm{mAl})$ units which can be assigned to quartz and rhyolitic glass $[56,65]$, to $\mathrm{K}$ feldspars [66] and metakaolinite. Metakaolinite main peak at $-101 \mathrm{ppm}$ is due to the $\mathrm{Q}^{4}(1 \mathrm{Al})$ coordination, whereas a secondary peak, observed at $-91 \mathrm{ppm}$, corresponds to 

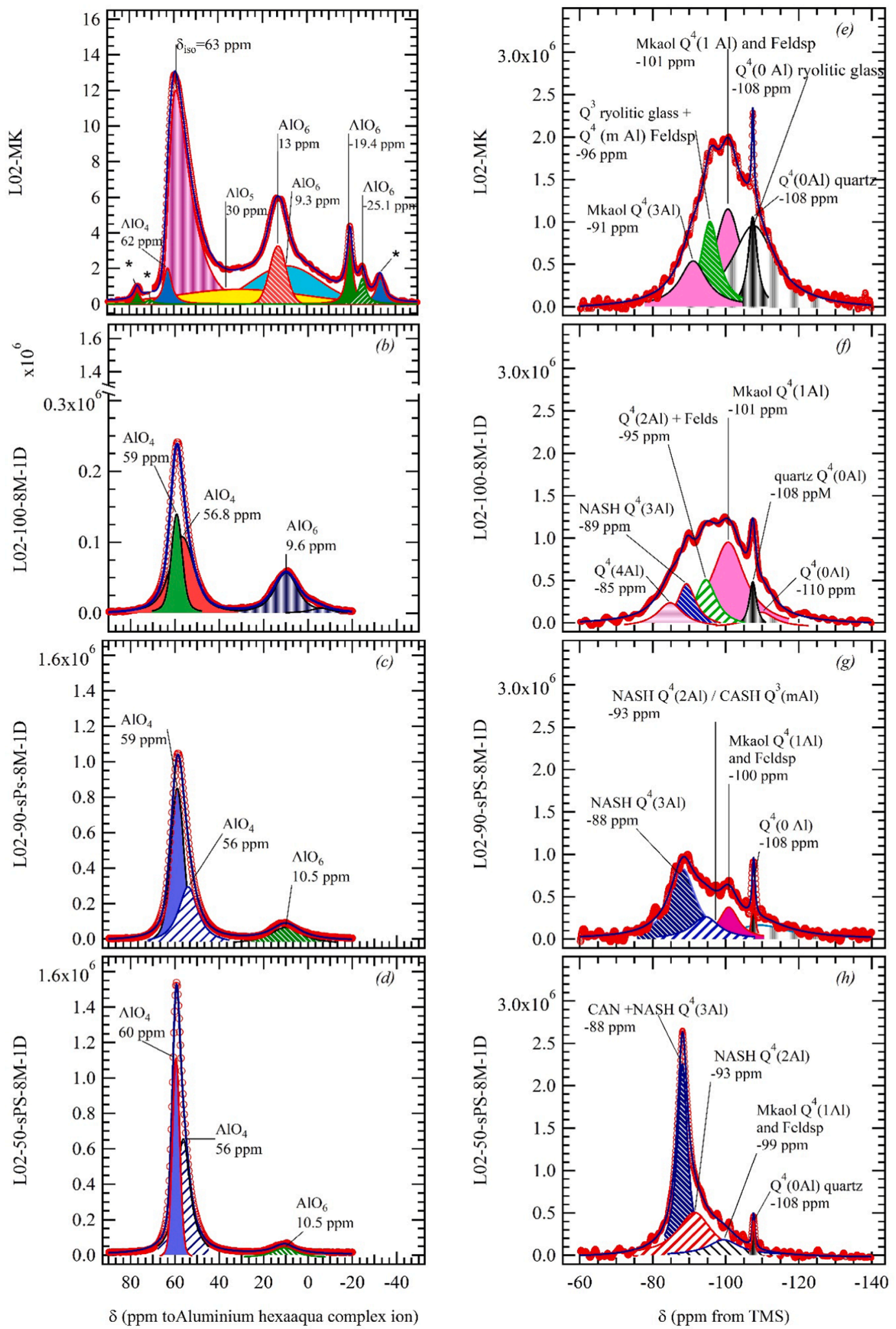

Fig. 6. ${ }^{27} \mathrm{Al}$ and ${ }^{29} \mathrm{Si}$ MAS NMR spectra including peak fit: (a) and (e) L02-MK; (b) and (f) L02-100-8M_1D; (c) and (g) L02-90-sPS-8M_1D; (d) and (h) L02-50-sPS8M_1D. Experimental spectra are reported as red circles, resulting fit as black lines. Each peak is filled with different color and texture for sake of clarity. Sidebands are starred and corresponding peaks in the fit are colored alike. Tentative assignments are also reported. (For interpretation of the references to color in this figure legend, the reader is referred to the web version of this article.) 
$\mathrm{Q}^{4}(3 \mathrm{Al})$ atomic coordination [67].

In the spectrum from sample L02-100-8M_1D (Fig. 6f), six signals are detected, some of which are new and appear at approximately -85 , $-89,-95,-101,-108$ and $-110 \mathrm{ppm}$. Resonance at $-108 \mathrm{ppm}$ is from crystalline quartz. According to earlier ${ }^{29} \mathrm{Si}$ NMR studies of aluminosilicate frameworks $[56,65]$, the other signals may be assigned to $\mathrm{Q}^{4}(4 \mathrm{Al})$, $\mathrm{Q}^{4}(3 \mathrm{Al}), \mathrm{Q}^{4}(2 \mathrm{Al}), \mathrm{Q}^{4}(1 \mathrm{Al})$ and $\mathrm{Q}^{4}(0 \mathrm{Al})$, respectively, from the formation of N-A-S-H. The signal at $-85 \mathrm{ppm}$ can be associated to unit $\mathrm{Q}^{4}(4 \mathrm{Al})$ with the formation of an Al-rich alkaline silico-aluminate gel, considered the local availability in solution of $\mathrm{Al}$ deriving from alunite decomposition, but also to the formation of nanocrystals of SOD zeolites. The peaks area was allowed to vary smoothly on the basis of thermodynamics of statistical distribution which prevents one $\mathrm{Q}^{4}(\mathrm{mAl})$ unit from having a more dominating presence than the neighboring $\left[\mathrm{Q}^{4}(\mathrm{~m}+1)\right.$ or $\left.\mathrm{Q}^{4}(\mathrm{~m}-1)\right]$ units in $\mathrm{Q}^{4}$ gel [68]. Unreacted materials also contribute to the observed signals and influence the relative intensities assigned to each $\mathrm{Q}^{4}(\mathrm{mAl})$ structural unit in the reaction products, thus preventing to determine the relative abundance of the various structural units in the gel. The fairly high intensity of the peak at $-101 \mathrm{ppm}$ may suggest the presence of unreacted metakaolinite.

A different shape in the spectrum profile is observed when $\mathrm{Ca}$ is present in the blend. In the spectra from L02-90-sPS-8M_1D (Fig. 6g) and L02-50-sPS-8M_1D (Fig. 6h) samples, the same system of peaks observed in L02-100-8M_1D is present, apart from the peak at $-85 \mathrm{ppm}$. Small differences in isomer shifts with respect to the L02-100-8M_1D can be due to the difference in $\mathrm{Si} / \mathrm{Al}$ ratio and to the presence of $\mathrm{Ca}$, which may partially substitute Na and prompt the formation of (N,C-A-S-H) like gel. Both spectra show two small resonances at -99 and $-93 \mathrm{ppm}$ and an intense peak at $-88 \mathrm{ppm}$.

Their assignment is not straightforward as resonances from $\mathrm{Q}^{4}(\mathrm{mAl})$ and $\mathrm{Q}^{3}(\mathrm{mAl})$ from $(\mathrm{N}, \mathrm{C})-\mathrm{A}-\mathrm{S}-\mathrm{H}$ and C-A-S-H may overlap. The signal at $-99 \mathrm{ppm}$ may be assigned to $\mathrm{Q}^{4}(1 \mathrm{Al})$ from the N-A-S-H gel, while the peak at -93 ppm might be related to both $\mathrm{Q}^{3}(1 \mathrm{Al})$ from C-A-S-H gel and to $\mathrm{Q}^{4}(2 \mathrm{Al})$ units in N-A-S-H gel. The most intense peak at $-88 \mathrm{ppm}$ is attributable to $\mathrm{Q}^{4}(3 \mathrm{Al})$, typical of N-A-S-H gel. According to literature, sodalite has a chemical shift of approximately $-85 \mathrm{ppm}$, while cancrinite of $-87.3 \mathrm{ppm}$, due to different $\mathrm{Si} / \mathrm{Al}$ ratio [69]. The contribution of theses zeolitic phases to the signal at $-88 \mathrm{ppm}$ might also be considered. Sodalite-type phases have not been observed by XRPD in this sample, however the presence of small amounts (below XRPD detection limit) of this zeolite cannot be excluded, as it has already been observed that SOD-type zeolite transforms into a CAN-type in zeolite synthesis [69].

Finally, the peak at $-88 \mathrm{ppm}$ dominates the spectrum of L02-50-sPS8M_1D (Fig. $6 \mathrm{~h}$ ). This may be associated with the formation of large amount of C-A-S-H gel, but more likely to the presence of cancrinite.

\subsection{Sulfate leaching}

Results of the leaching experiments performed on samples aged 28 days are reported in Table 3.

The amount of sulfate measured in solution in the sample L02-100$8 \mathrm{M}$ 28D indicates that nearly all $\mathrm{SO}_{4}^{2-}$ present in the initial mixture precipitates as water-soluble thenardite when the excess of water

Table 3

Solubility of sulfate ion in leaching tests.

\begin{tabular}{clll}
\hline Samples & $\begin{array}{l}\mathrm{SO}_{4}^{2-} \text { in } 1 \mathrm{~g} \text { of the } \\
\text { initial solid mix } \\
(\mathrm{g})\end{array}$ & $\begin{array}{l}\mathrm{SO}_{4}^{2-} \text { measured in } \\
\text { the liquid }(\mathrm{ppm})\end{array}$ & $\begin{array}{l}\mathrm{SO}_{4}^{2-} \text { retained in the } \\
\text { solid after leaching }(\mathrm{wt} \\
\%)\end{array}$ \\
$\begin{array}{c}\text { L02-100- } \\
\text { 8M_28D }\end{array}$ & 0.043 & 1972.550 & 7.82 \\
$\begin{array}{c}\text { L02-90-sPS- } \\
\text { 8M_28D }\end{array}$ & 0.039 & 880.772 & 54.27 \\
$\begin{array}{c}\text { L02-50-sPS- } \\
\text { 8M_28D }\end{array}$ & 0.021 & 334.300 & 68.76 \\
\hline
\end{tabular}

evaporates. Addition of sPS_800 to the reacting mixture increases sulfate retention by the solid AAMs. In fact, the sulfate retention goes from 54 $\mathrm{wt} \%$ by adding just $10 \mathrm{wt} \%$ of sPS_800 to the starting mixture, to $69 \mathrm{wt} \%$ in the paste prepared with $50 \mathrm{wt} \%$ of sPS_800.

Sulfate can be trapped into zeolites structures and, if one considers the N-A-S-H gel as composed by nanocrystalline X-ray amorphous zeolites, it might be suggested that the gel itself can also retain sulfate. Actually, XRPD patterns show the presence of CAN-type zeolites in L0290-sPS-8M and L02-50-sPS_8M. The higher sulfate retention of the latter sample can be due to the presence of U-phase. Calcium sulfo-aluminate hydrates can be the vehicles able to reduce sensibly sulfate leaching due to the reaction between $\mathrm{SO}_{4}^{2-}$ and $\mathrm{CaO}$.

\subsection{Effect of calcium and sulfate}

The presence of sulfate and free alumina have negative effects on the activation process of the sole kaolinitic clay. The results of ${ }^{29} \mathrm{Si} \mathrm{NMR}$ show a relatively low degree of reaction in paste L02-100-8M_1D, in fact, the spectrum obtained is quite similar to that of the original L02-MK. This may be largely associated with the depletion of $\mathrm{Na}$ by forming thernardite, which is easily leached out.

In alkaline aluminosilicate solutions with $\mathrm{Si} / \mathrm{Al}<1$, the majority of aluminum is present in the form of $\mathrm{Al}(\mathrm{OH})^{4-}(\mathrm{aq})$ [70]. Studies of aluminosilicates dissolution have shown that there is an initial high rate of aluminum dissolution, followed by stoichiometric release of silicon and aluminum [71]. The presence of aluminum deriving from alunite dehydroxylation in solution may limit the dissolution rate of metakaolin; this in turn causes a limited availability of $\mathrm{Si}$ in solution, which hinders N-A-S-H precipitation. In L02-100-8M, the precipitation of gibbsite has also been observed, which causes the amount of reactive aluminum to decrease to form a gel. All this explains to a large extent the low mechanical resistance obtained by this material.

The presence of a small amount of $\mathrm{CaO}$ in the system (L02-90-sPS$8 \mathrm{M}, 10 \mathrm{wt} \%$ of sPS, which corresponds to $2 \mathrm{wt} \%$ of $\mathrm{CaO}$ in the mixture) is capable of appreciably reducing the solubility of sulfate (more than 50 $\mathrm{wt} \%$ ), and clearly, has positive effects on the mechanical development. The presence of calcium, instead of thernardite and gibbsite, seems to favor the formation of zeolites that can incorporate some calcium and sulfur, and the formation of a larger quantity of gels or mixture of gels $\mathrm{N}$ A-S-H and (N,C)-A-S-H.

A larger increase of calcium content to the system (L02-50-sPS-8M, corresponding to $9.8 \mathrm{wt} \%$ of lime in the system) increases the sulfate retention to up to $70 \mathrm{wt} \%$. These effects could be attributed to the formation of crystalline products, e.g., CAN type zeolites or sulfo-aluminate compounds as U-Phase, as observed by the XRPD analysis. However, this material, as mentioned in section 3.1, presents a very fast initial reaction that is exothermic and causes a fast hardening of the paste. This in turn makes it difficult to pour the paste into the mold and measure the mechanical properties. This process may be due to a rapid formation of AFm phases although studies at early ages would be necessary.

Therefore, the heat treatment of the Pietra Serena sludge has revealed to be an important step of the process, as the resulting $\mathrm{CaO}$ is clearly highly reactive. The main reaction product of the activation of blends of the heat-treated precursors is a mixture of (N,C)-A-S-H and CA-S-H species forming a condensed gel network surrounding the unreacted mineral particles, with resulting mechanical properties higher than that of the product of the activation of the sole L02-MK clay. The effect is opposite to what observed by Clausi et al. [29], who observed a reduction of strength with the increase of untreated SPS sludge in MKbased mortars, due to a limited formation of an alumino-silicate gel from Pietra Serena sludge. In this respect, it would be worth investigating the reactivity of the heat-treated sPS towards metakaolin in a model system without sulfate, like that of Clausi et al. [29].

Another important effect of $\mathrm{Ca}$ in the system is the retention of important percentages of sulfate ions present in the starting material by the gel matrix and secondary products, such as cancrinite and calcium 
sulfo-aluminate hydrates. Both calcium sulfo-aluminate hydrates and cancrinite have the ability to combine with a number of cations and anions, which makes them important with regard to waste immobilization in cementitious matrices [34,72-74]. These binders develop sufficient strength for waste immobilization applications. Formation of cancrinite and U-Phase are considered to be desirable for nuclear waste encapsulation via cementation. Moreover, experiments made by maintaining the calcium content fixed in the system and varying the alkalinity of the solution might further lead to the formation of ettringite instead of U-Phase, which also occurs in calcium sulfo-aluminate cements to produce special binders, such as shrinkage-resistant and selfstressing cements, and could further improve the properties of the composites.

\section{Conclusions}

The search for alternative precursors is key towards both the reduction of the carbon footprint of the alkali activation process and the long-term secure supply of the materials for the cement production. This study has demonstrated that two different raw materials, a sulfatebearing kaolinitic clay and Pietra Serena sludge, can be used to produce sustainable construction materials. Moreover, it has reinforced the awareness that systematic recovery of residual sludge from mining and stone cultivation is a way of implementing environmental safeguard and conservation of non-renewable resources.

The results obtained have demonstrated that:

- an alkaline cement can be synthesized by alkali activation of blends of sludge of Pietra Serena sandstone and sulfate-bearing kaolinitic clay after thermal treatment;

- calcium oxide produced by sPS decarbonation is hydrated and reacts with silica;

- the best values of compressive strength after one day of curing at $85{ }^{\circ} \mathrm{C}$ is obtained for sample with $2 \mathrm{wt} \%$ of $\mathrm{CaO}$ in the mix, with values that are three times higher than those of L02-MK activated with $\mathrm{NaOH}$;

- in the mixtures with sPS_800, interaction between the different precursors occurs, giving rise to a mixture of (N,C)-A-S-H/C-A-S-H gels, similar to those produced in so-called mixed alkali cements or hybrid cements;

- calcium sulfo-aluminate hydrate phases, such as AFm compound, and CAN-type zeolites also form. These both can trap sulfate from the clay.

Further studies at both earlier and longer age will allow to better understanding the reaction process. Studies carried out at lower $\mathrm{pH}$ would allow evaluating the effect of ettringite formation and contributing to the reduction of the carbon footprint of the activating solution.

\section{CRediT authorship contribution statement}

Roberta Occhipinti: Investigation, Data curation, Formal analysis, Writing - original draft, Visualization. Ana M. Fernández-Jiménez: Conceptualization, Methodology, Investigation, Writing - review \& editing, Project administration, Funding acquisition. Angel Palomo: Conceptualization, Methodology, Writing - review \& editing, Funding acquisition. Serena C. Tarantino: Conceptualization, Methodology, Formal analysis, Writing - original draft, Writing - review \& editing, Visualization, Project administration, Funding acquisition. Michele Zema: Conceptualization, Methodology, Writing - review \& editing.

\section{Declaration of Competing Interest}

The authors declare that they have no known competing financial interests or personal relationships that could have appeared to influence the work reported in this paper.

\section{Acknowledgements}

The authors wish to thank the suppliers of the materials utilized for the present work: Eurit s.r.l. (L02 clay) and Pietra Serena Group s.r.l. (Pietra Serena). Ministero dell'Istruzione, dell'Università e della Ricerca is thanked for the scholarship "Fondo per il sostegno dei giovani". This research was also funded by the Spanish Ministry of Science and Innovation under research project PID2019-111464RB-I00, and by the Italian Ministry of Economic Development (D.M. 5 March 2018_CHAPTER II-Call for Research and Development Projects within the application areas consistent with the National Strategy of Intelligent Specialization [SNSI]-Smart Factory), under the Project I.E.S.MAN. (Internet of Enterprise Sustainable Manufacturing) n. 211.

\section{References}

[1] C. Shi, B. Qu, J.L. Provis, Recent progress in low-carbon binders, Cem. Concr. Res. 122 (2019) 227-250, https://doi.org/10.1016/j.cemconres.2019.05.009.

[2] J.L. Provis, A. Palomo, Advances in understanding alkali-activated materials, Cem. Concr. Res. 78 (2015) 110-125, https://doi.org/10.1016/j. cemconres.2015.04.013.

[3] C. Shi, Alkali-Activated Cements and Concretes, CRC Press (2003), https://doi.org/ 10.1201/9781482266900.

[4] F. Pacheco-Torgal, J. Labrincha, C. Leonelli, A. Palomo, P. Chindaprasit, Handbook of Alkali-Activated Cements, Mortars and Concretes, Woodhead Publishing, 2014 http://125.234.102.150:8080/dspace/handle/dnulib_52011/8031.

[5] [5] J.L. Provis, J.S.J. van Deventer, Alkali Activated Materials: State-of-the-Art Report, RILEM TC 224-AAM, 2014. 10.1007/978-94-007-7672-2.

[6] B.C. McLellan, R.P. Williams, J. Lay, A. Van Riessen, G.D. Corder, Costs and carbon emissions for geopolymer pastes in comparison to ordinary portland cement, J. Clean. Prod. 19 (2011) 1080-1090, https://doi.org/10.1016/j. jclepro.2011.02.010.

[7] L.K. Turner, F.G. Collins, Carbon dioxide equivalent (CO2-e) emissions: A comparison between geopolymer and OPC cement concrete, Constr. Build. Mater. 43 (2013) 125-130, https://doi.org/10.1016/j.conbuildmat.2013.01.023.

[8] P. Shoaei, H.R. Musaeei, F. Mirlohi, S. Narimani zamanabadi, F. Ameri, N. Bahrami, Waste ceramic powder-based geopolymer mortars: Effect of curing temperature and alkaline solution-to-binder ratio, Constr. Build. Mater. 227 (2019) 116686. 10.1016/j.conbuildmat.2019.116686.

[9] A. Fernández-Jiménez, N. Cristelo, T. Miranda, Á. Palomo, Sustainable alkali activated materials: Precursor and activator derived from industrial wastes, J. Clean. Prod. 162 (2017) 1200-1209, https://doi.org/10.1016/j. jclepro.2017.06.151.

[10] S. Rajaei, P. Shoaei, M. Shariati, F. Ameri, H.R. Musaeei, B. Behforouz, J. de Brito, Rubberized alkali-activated slag mortar reinforced with polypropylene fibres for application in lightweight thermal insulating materials, Constr. Build. Mater. 270 (2021), https://doi.org/10.1016/j.conbuildmat.2020.121430.

[11] B. Coppola, C. Tardivat, S. Richaud, J.-M. Tulliani, L. Montanaro, P. Palmero, Alkali-activated refractory wastes exposed to high temperatures: development and characterization, J. Eur. Ceram. Soc. 40 (2020) 3314-3326, https://doi.org/ 10.1016/j.jeurceramsoc.2020.02.052.

[12] H. Hamdane, Y. Tamraoui, S. Mansouri, M. Oumam, A. Bouih, T. El Ghailassi, R. Boulif, B. Manoun, H. Hannache, Statistical modeling of geopolymers from dualalkali activation of un-calcined phosphate sludge and their potential applications as sustainable coating materials, J. Clean. Prod. 283 (2021), https://doi.org/ 10.1016/j.jclepro.2020.125421.

[13] L. Simão, D. Hotza, M.J. Ribeiro, R.M. Novais, O.R.K. Montedo, F. Raupp-Pereira, Development of new geopolymers based on stone cutting waste, Constr. Build. Mater. 257 (2020), https://doi.org/10.1016/j.conbuildmat.2020.119525.

[14] S.A. Bernal, E.D. Rodríguez, A.P. Kirchheim, J.L. Provis, Management and valorisation of wastes through use in producing alkali-activated cement materials, J. Chem. Technol. Biotechnol. 91 (2016) 2365-2388, https://doi.org/10.1002/ jctb.4927.

[15] R.A. Antunes Boca Santa, A.M. Bernardin, H.G. Riella, N.C. Kuhnen, Geopolymer synthetized from bottom coal ash and calcined paper sludge, J. Clean. Prod. 57 (2013) 302-307. 10.1016/j.jclepro.2013.05.017.

[16] I. Perná, T. Hanzlícek, The solidification of aluminum production waste in geopolymer matrix, J. Clean. Prod. 84 (2014) 657-662, https://doi.org/10.1016/j. jclepro.2014.04.043.

[17] K. Komnitsas, D. Zaharaki, Geopolymerisation: A review and prospects for the minerals industry, Miner. Eng. 20 (2007) 1261-1277, https://doi.org/10.1016/j. mineng.2007.07.011.

[18] F. Ameri, P. Shoaei, S.A. Zareei, B. Behforouz, Geopolymers vs. alkali-activated materials (AAMs): A comparative study on durability, microstructure, and resistance to elevated temperatures of lightweight mortars, Constr. Build. Mater. 222 (2019) 49-63. 10.1016/j.conbuildmat.2019.06.079.

[19] P. Shoaei, F. Ameri, H. Reza Musaeei, T. Ghasemi, C.B. Cheah, Glass powder as a partial precursor in Portland cement and alkali-activated slag mortar: A comprehensive comparative study, Constr. Build. Mater. 251 (2020) 118991. 10.1016/j.conbuildmat.2020.118991. 
[20] F. Ameri, P. Shoaei, H. Reza Musaeei, S. Alireza Zareei, C.B. Cheah, Partial replacement of copper slag with treated crumb rubber aggregates in alkaliactivated slag mortar, Constr. Build. Mater. 256 (2020) 119468. 10.1016/j. conbuildmat.2020.119468.

[21] M. Shariati, A. Shariati, N.T. Trung, P. Shoaei, F. Ameri, N. Bahrami, S. N. Zamanabadi, Alkali-activated slag (AAS) paste: Correlation between durability and microstructural characteristics, Constr. Build. Mater. 267 (2021), https://doi org/10.1016/j.conbuildmat.2020.120886.

[22] C. Montani, XXIX Rapporto marmo e pietre nel mondo 2018 (2018). http://www. worldstonereport.com.

[23] B. Coppola, J.-M. Tulliani, P. Antonaci, P. Palmero, Role of Natural Stone Wastes and Minerals in the Alkali Activation Process: A Review, Materials (Basel). 13 (2020) 2284, https://doi.org/10.3390/ma13102284.

[24] K.R. O'Brien, J. Ménaché, L.M. O'Moore, Impact of fly ash content and fly ash transportation distance on embodied greenhouse gas emissions and water consumption in concrete, Int. J. Life Cycle Assess. 14 (2009) 621-629, https://doi org/10.1007/s11367-009-0105-5.

[25] M. Weil, K. Dombrowski, A. Buchwald, Life-cycle analysis of geopolymers, Woodhead Publishing (2009), https://doi.org/10.1533/9781845696382.2.194.

[26] S.A. Bernal, P.V. Krivenko, J.L. Provis, F. Puertas, W.D.A. Rickard, C. Shi, A. van Riessen, Other potential applications for alkali-activated materials, RILEM State-ofthe-Art Reports. 13 (2014) 339-379, https://doi.org/10.1007/978-94-007-7672-2 12.

[27] T. Luukkonen, A. Heponiemi, H. Runtti, J. Pesonen, J. Yliniemi, U. Lassi, Application of alkali-activated materials for water and wastewater treatment: a review, Rev. Environ. Sci. Biotechnol. 18 (2019) 271-297, https://doi.org/ 10.1007/s11157-019-09494-0.

[28] I. Lancellotti, L. Barbieri, C.L.-H. of A.-A. Cements, U. 2015, Use of alkali-activated concrete binders for toxic waste immobilization, in: Elsevier, 2015: pp. 539-554. https://www.sciencedirect.com/science/article/pii/B9781782422761500204.

[29] M. Clausi, A.M. Fernández-Jiménez, A. Palomo, S.C. Tarantino, M. Zema, Reuse of waste sandstone sludge via alkali activation in matrices of fly ash and metakaolin, Constr. Build. Mater. 172 (2018) 212-223, https://doi.org/10.1016/j. conbuildmat.2018.03.221.

[30] E. Gasparini, S.C. Tarantino, M. Conti, R. Biesuz, P. Ghigna, F. Auricchio, M. P. Riccardi, M. Zema, Geopolymers from low-T activated kaolin: Implications for the use of alunite-bearing raw materials, Appl. Clay Sci. 114 (2015) 530-539, https://doi.org/10.1016/j.clay.2015.06.040.

[31] J. Kristóf, R.L. Frost, S.J. Palmer, E. Horváth, E. Jakab, Thermoanalytical studies of natural potassium, sodium and ammonium alunites, J. Therm. Anal. Calorim. 100 (2010) 961-966, https://doi.org/10.1007/s10973-009-0581-7.

[32] W.K.W. Lee, J.S.J. van Deventer, The effects of inorganic salt contamination on the strength and durability of geopolymers, Colloids Surfaces A Physicochem. Eng. Asp. 211 (2002) 115-126, https://doi.org/10.1016/S0927-7757(02)00239-X.

[33] M. Criado, A.F. Jiménez, A. Palomo, Effect of sodium sulfate on the alkali activation of fly ash, Cem. Concr. Compos. 32 (2010) 589-594, https://doi.org/ 10.1016/j.cemconcomp.2010.05.002.

[34] C. Desbats-Le Chequer, F. Frizon, Impact of sulfate and nitrate incorporation on potassium- and sodium-based geopolymers: Geopolymerization and materials properties, J. Mater. Sci. 46 (2011) 5657-5664, https://doi.org/10.1007/s10853011-5516-6.

[35] K. Komnitsas, D. Zaharaki, G. Bartzas, Effect of sulphate and nitrate anions on heavy metal immobilisation in ferronickel slag geopolymers, Appl. Clay Sci. 73 (2013) 103-109, https://doi.org/10.1016/j.clay.2012.09.018.

[36] C. Ruiz-Santaquiteria, A. Fernández-Jiménez, J. Skibsted, A. Palomo, Clay reactivity: Production of alkali activated cements, Appl. Clay Sci. 73 (2013) 11-16, https://doi.org/10.1016/j.clay.2012.10.012.

[37] V.F.F. Barbosa, K.J.D. MacKenzie, C. Thaumaturgo, Synthesis and characterisation of materials based on inorganic polymers of alumina and silica: Sodium polysialate polymers, Int. J. Inorg. Mater. 2 (2000) 309-317, https://doi.org/10.1016/S1466 6049(00)00041-6.

[38] M. Rowles, B. O'Connor, Chemical optimisation of the compressive strength of aluminosilicate geopolymers synthesised by sodium silicate activation of metakaolinite, J. Mater. Chem. 13 (2003) 1161-1165, https://doi.org/10.1039/ b212629j.

[39] R.A. Fletcher, K.J.D. MacKenzie, C.L. Nicholson, S. Shimada, The composition range of aluminosilicate geopolymers, J. Eur. Ceram. Soc. 25 (2005) 1471-1477, https://doi.org/10.1016/j.jeurceramsoc.2004.06.001.

[40] G. Li, P. Le Bescop, M. Moranville, The U phase formation in cement-based systems containing high amounts of Na2SO4, Cem. Concr. Res. (1996), https://doi.org/ 10.1016/0008-8846(95)00189-1.

[41] B.A. Clark, P.W. Brown, The formation of calcium sulfoaluminate hydrate compounds: Part I, Cem. Concr. Res. 29 (1999) 1943-1948, https://doi.org/ 10.1016/S0008-8846(99)00200-8.

[42] B.A. Clark, P.. W. Brown, Formation of calcium sulfoaluminate hydrate compounds. Part II, Cem. Concr. Res. 30 (2000) 1943-1948. 10.1016/S0008-8846 (99)00234-3.

[43] J. Moon, S. Yoon, P.J.M. Monteiro, Mechanical properties of jennite: A theoretical and experimental study, Cem. Concr. Res. 71 (2015) 106-114, https://doi.org/ 10.1016/j.cemconres.2015.02.005.

[44] J.L. Provis, G.C. Lukey, J.S.J. Van Deventer, Do geopolymers actually contain nanocrystalline zeolites? a reexamination of existing results, Chem. Mater. 17 (2005) 3075-3085, https://doi.org/10.1021/cm050230i.

[45] Y. Deng, J.B. Harsh, M. Flury, J.S. Young, J.S. Boyle, Mineral formation during simulated leaks of Hanford waste tanks, Appl. Geochemistry. 21 (2006) 1392-1409, https://doi.org/10.1016/j.apgeochem.2006.05.002.
[46] H. Taylor, Cement chemistry, 1997. https://www.icevirtuallibrary.com/doi/pdf/ $10.1680 /$ cc.25929.fm.

[47] T. Slamečka, F. Škvára, The effect of water ratio on microstructure and composition of the hydration products of portland cement pastes, Ceram. Silikáty. 46 (2002) 152-158. https://www.irsm.cas.cz/materialy/cs_content/ 2002/Slamecka_CS_2002_0000.pdf.

[48] J. Dong, L. Wang, T. Zhang, Study on the strength development, hydration process and carbonation process of $\mathrm{NaOH}$-activated Pisha Sandstone, Constr. Build. Mater. 66 (2014) 154-162, https://doi.org/10.1016/j.conbuildmat.2014.05.075.

[49] C. Li, T. Zhang, L. Wang, Mechanical properties and microstructure of alkali activated Pisha sandstone geopolymer composites, Constr. Build. Mater. 68 (2014) 233-239, https://doi.org/10.1016/j.conbuildmat.2014.06.051.

[50] X. Pardal, I. Pochard, A. Nonat, Experimental study of Si-Al substitution in calcium-silicate-hydrate (C-S-H) prepared under equilibrium conditions, Cem. Concr. Res. 39 (2009) 637-643, https://doi.org/10.1016/j. cemconres.2009.05.001.

[51] I. García-Lodeiro, A. Fernández-Jiménez, A. Palomo, D.E. Macphee, Effect of Calcium Additions on N-A-S-H Cementitious Gels, J. Am. Ceram. Soc. 93 (2010) 1934-1940, https://doi.org/10.1111/j.1551-2916.2010.03668.x.

[52] I. Garcia-Lodeiro, A. Palomo, A. Fernández-Jiménez, D.E. Macphee, Compatibility studies between N-A-S-H and C-A-S-H gels. Study in the ternary diagram Na2O-CaO-Al2O3-SiO2-H2O, Cem. Concr. Res. 41 (2011) 923-931, https://doi. org/10.1016/j.cemconres.2011.05.006.

[53] C.K. Yip, G.C. Lukey, J.S.J. Van Deventer, The coexistence of geopolymeric gel and calcium silicate hydrate at the early stage of alkaline activation, Cem. Concr. Res. 35 (2005) 1688-1697, https://doi.org/10.1016/j.cemconres.2004.10.042.

[54] C.K. Yip, G.C. Lukey, J.L. Provis, J.S.J. van Deventer, Effect of calcium silicate sources on geopolymerisation, Cem. Concr. Res. 38 (2008) 554-564, https://doi. org/10.1016/j.cemconres.2007.11.001.

[55] J.B. d'Espinose de Lacaillerie, C. Fretigny, D. Massiot, MAS NMR spectra of quadrupolar nuclei in disordered solids: The Czjzek model, J. Magn. Reson. 192 (2008) 244-251, https://doi.org/10.1016/j.jmr.2008.03.001.

[56] [56] G. Engelhardt, D. Michel, High-resolution solid-state NMR of silicates and zeolites, 1987. https://www.osti.gov/biblio/6743230.

[57] J. Rocha, J. Klinowski, 29Si and 27Al magic-angle-spinning NMR studies of the thermal transformation of kaolinite, Phys. Chem. Miner. 17 (1990) 179-186, https://doi.org/10.1007/BF00199671.

[58] A. Buchwald, H. Hilbig, C. Kaps, Alkali-activated metakaolin-slag blends - performance and structure in dependence of their composition, J. Mater. Sci. 42 (2007) 3024-3032, https://doi.org/10.1007/s10853-006-0525-6.

[59] C. Pecharromán, I. Sobrados, J.E. Iglesias, T. González-Carreñ, J. Sanz, Thermal Evolution of Transitional Aluminas Followed by NMR and IR Spectroscopies, ACS Publ. 103 (1999) 6160-6170, https://doi.org/10.1021/jp983316q.

[60] J. Jiao, J. Kanellopoulos, W. Wang, S.S. Ray, H. Foerster, D. Freude, M. Hunger, Characterization of framework and extra-framework aluminum species in nonhydrated zeolites Y by 27Al spin-echo, high-speed MAS, and MQMAS NMR spectroscopy at B0 $=9.4$ to $17.6 \mathrm{~T}$, T Artic, Phys. Chem. Chem. Phys. (2005), https://doi.org/10.1039/b508358c.

[61] U.G. Nielsen, J. Majzlan, B. Phillips, M. Ziliox, C.P. Grey, Characterization of defects and the local structure in natural and synthetic alunite (K, Na, H3O) Al3 (SO4) $(\mathrm{OH}) 6$ by multi-nuclear solid-state NMR spectroscopy, Am. Mineral. 92 (2007) 587-597, https://doi.org/10.2138/am.2007.2414.

[62] [62] I. Garcia-Lodeiro, A. Palomo, A. Fernández-Jiménez, An overview of the chemistry of alkali-activated cement-based binders, in: Handb. Alkali-Activated Cem. Mortars Concr., Elsevier, 2015: pp. 19-47. https://doi.org/10.1533/ 9781782422884.1.19.

[63] T. Isobe, T. Watanabe, J.B. D'Espinose de la Caillerie, A.P. Legrand, D. Massiot, Solid-state $1 \mathrm{H}$ and 27Al NMR studies of amorphous aluminum hydroxides, J. Colloid Interface Sci. 261 (2003) 320-324, https://doi.org/10.1016/S00219797(03)00144-9.

[64] Y. Shimada, J.F. Young, Thermal stability of ettringite in alkaline solutions at 80 ${ }^{\circ} \mathrm{C}$, Cem. Concr. Res. 34 (2004) 2261-2268, https://doi.org/10.1016/j. cemconres.2004.04.008.

[65] K.J.D. MacKenzie, M.E. Smith, Multinuclear solid-state NMR of inorganic materials, Pergamon, 2002.

[66] G. Anbalagan, G. Sankari, S. Ponnusamy, R.T. Kumar, S. Gunasekaran, Investigation of silicate mineral sanidine by vibrational and NMR spectroscopic methods, Spectrochim. Acta Part A Mol. Biomol. Spectrosc. 74 (2009) 404-409, https://doi.org/10.1016/j.saa.2009.06.034.

[67] J. Klinowski, Nuclear magnetic resonance studies of zeolites, Prog. Nucl. Magn. Reson. Spectrosc. 16 (1984) 237-309, https://doi.org/10.1016/0079-6565(84) 80007-2.

[68] J.L. Provis, P. Duxson, G.C. Lukey, J.S.J. Van Deventer, Statistical thermodynamic model for Si/Al ordering in amorphous aluminosilicates, Chem. Mater. 17 (2005) 2976-2986, https://doi.org/10.1021/cm050219i.

[69] C.A.R. Reyes, C. Williams, O.M.C. Alarcón, Nucleation and growth process of sodalite and cancrinite from kaolinite-rich clay under low-temperature hydrothermal conditions, Mater. Res. 16 (2013) 424-438, https://doi.org/ 10.1590/S1516-14392013005000010.

[70] N. Azizi, R.K. Harris, A. Samadi-Maybodi, Aluminium-27 NMR investigation of the influence of cation type on aluminosilicate solutions, Magn. Reson. Chem. 40 (2002) 635-639, https://doi.org/10.1002/mrc.1071.

[71] E. Oelkers, J. Schott, J.L. Devidal, The effect of aluminum, $\mathrm{pH}$, and chemical affinity on the rates of aluminosilicate dissolution reactions, Geochim. Cosmochim. Acta. 59 (9) (1994) 2011-2020. https://www.sciencedirect.com/science/article/p ii/001670379490281X. 
[72] M.L.D. Gougar, B.E. Scheetz, D.M. Roy, Ettringite and C-S-H portland cement phases for waste ion immobilization: A review, Waste Manag. 16 (1996) 295-303, https://doi.org/10.1016/S0956-053X(96)00072-4.

[73] M. Fechtelkord, B. Posnatzki, B. Josef-Christian, Characterization of basic cancrinite synthesized in a butanediol-water system, Eur. J. Mineral. 15 (2003) 589-598, https://doi.org/10.1127/0935-1221/2003/0015-0589.
[74] N.B. Milestone, Reactions in cement encapsulated nuclear wastes: need for toolbox of different cement types, Adv. Appl. Ceram. 105 (2006) 13-20, https://doi.org/ $10.1179 / 174367606$ X81678. 